ESCRITAS Vol. 9 n. 2 (2017) ISSN 2238-7188 p. 194-209

\title{
"TEMOS PROFESSORES COM FORMAÇÃO NOS ESTADOS UNIDOS!": O VALOR DO CURSO DE INGLÊS NO EXTERIOR
}

\author{
“WE HAVE TEACHERS WHO STUDIED IN THE UNITED \\ STATES!”: THE VALUE OF STUDYING ENGLISH ABROAD
}

Edna Sousa Cruz ${ }^{1}$

\begin{abstract}
RESUMO: Este estudo abordou a internacionalização do ensino básico tendo como referência o Programa de Desenvolvimento para Professores de Inglês-PDPI. Como metodologia norteadora da análise dos dados, o estudo utilizou a História Oral por meio da qual foi feita a análise interpretativa da narrativa dos entrevistados. Os dados apontam que, no contexto de globalização, o PDPI figura como estratégia de internacionalização da educação básica tendo como principal instrumento o ensino da língua inglesa.
\end{abstract}

PALAVRAS-CHAVE: intercâmbio; professor de inglês; PDPI; Fulbright.

ABSTRACT: This study approached the internationalization of basic education having as reference the Program of Development for English Teachers-PDPI. As a guiding methodology for data analysis, the study used the Oral History through which an interpretative analysis of the interviewees' narrative was made. The data showed that in the context of globalization the PDPI is a strategy for internationalization of basic education, having as main tool thee English language teaching.

KEYWORDS: Interchange; english teacher; PDPI; Fulbright.

\section{INTRODUÇÃO}

Não é de hoje que se observa a presença de ações da política dos Estados Unidos influenciando os rumos da educação no Brasil. Precisamente, tomo como referência a década de 1940, marcada por conflitos de toda ordem em decorrência da Segunda Guerra Mundial. Alemanha e Estados Unidos - potências mundiais protagonizaram a luta em defesa de seus interesses comerciais, políticos e ideológicos. $\mathrm{Na}$

\footnotetext{
${ }^{1}$ Doutora em Letras pela Universidade Federal do Tocantins-UFT. Professora de Língua Inglesa da Universidade Estadual da Região Tocantina do Maranhão-UEMASUL. edna.s.cruz@hotmail.com.
} 
busca por aliados, a América Latina foi considerada, por ambas as nações, terreno fértil para manter e propagar sua hegemonia - cada uma a sua maneira.

O Brasil foi um dos países em que as duas potências acima mencionadas, mais se empenharam para firmar aliança. Grande parte desses interesses derivou de questões econômicas, a exemplo do fornecimento de matéria-prima como borracha, manganês, minério de ferro e plantas medicinais, para citar algumas. Contudo, mesmo numa posição "privilegiada" que passou a ocupar na relação com Estados Unidos e Alemanha, o Brasil procurou manter um equilíbrio pragmático, embora acabasse se aliando ao poder do que Tota (2014) chama de "imperialismo sedutor" dos Estados Unidos.

Para "selar" a amizade com o Brasil e os demais países da América Latina, os Estados Unidos acenaram com a chamada good neighbor policy (política da boa vizinhança). De acordo com Moura (1984), ser bons vizinhos significaria, dentre outras coisas, uma política de troca generalizada de produtos, bens culturais entre os Estados Unidos e a América Latina. Como sustenta esse autor, os brasileiros

\begin{abstract}
Aprenderam a substituir os sucos de frutas tropicais onipresentes à mesa por uma bebida de gosto estranho e artificial chamada Coca-Cola. Começaram também a trocar os sorvetes feitos em pequenas sorveterias por um sucedâneo chamado Kibon, produzido por uma companhia que se deslocara às pressas da Ásia, por efeito da Guerra. Aprenderam a mascar uma goma elástica chamada chiclets e começaram a usar palavras novas que foram se incorporando à sua língua falada e escrita. Passaram a ouvir foxtrot, o jazz, o boogie-woogie entre outros ritmos e começaram a ver muitos mais filmes produzidos em Hollywood. Passaram a voar nas asas da Panair (Pan American), deixando para trás os aeroplanos da Lati e da Condor (MOURA, 1984, p. 9).
\end{abstract}

Sob a presidência de Franklin Delano Roosevelt, os Estados Unidos elaboraram um planejamento arrojado de penetração ideológica para marcar sua presença no território latino-americano. A intenção era assegurar a adesão do Brasil ao projeto de afirmação dos Estados Unidos como "[...] grande potência e centro de um novo sistema de poder no plano internacional”’2 (MOURA, 1984, p. 12). Não por acaso, foi criado o Office of the Coordinator of Inter American Affairs (doravante OCIAA), uma das maiores e mais engenhosas agências do governo americano.

Os esforços empreendidos pelo OCIAA para estreitar laços com o Brasil podem ser percebidos em quase todas as áreas, sobretudo no âmbito cultural. A cultura,

\footnotetext{
${ }^{2}$ Hertsgaard (2003, p. 41) diz que a Segunda Guerra Mundial ampliou a influência e liderança dos Estados Unidos, cuja economia foi "a única [...] que surgiu da guerra mais saudável do que destruída, montando um cenário para sua exploração numa prosperidade sem precedentes na história humana”.
} 
a propaganda e os meios de comunicação indissociáveis eram armas tão poderosas quanto os armamentos bélicos. A seu favor, o OCIAA dispunha da força dos veículos nacionais de comunicação de massa e do aparato da divisão de informação que atuou em frentes como as do rádio, da imprensa e do cinema. Cada um a sua maneira atuou de modo ostensivo e intensivo para conquistar o subcontinente por meio de corações e mentes (TOTA, 2014) e concretizar o projeto hegemônico e de consolidação dos Estados Unidos de "americanizar" o Brasil.

Também a divisão de ciência e educação da OCIAA ocupou-se em incutir nas comunidades científica e educacional o modelo americano de atuação. Uma estratégia utilizada para esse objetivo foi distribuir literatura técnica e livros que ilustravam a imagem de si que os Estados Unidos se empenhavam em propagar com esmero; ou seja, de uma sociedade bem-sucedida, que deveria ser exposta à visitação das outras Américas.

A esses elementos de publicização de uma cultura e um ideário soma-se a oferta de viagens a profissionais brasileiros de segmentos diversos para que "[...] observassem com seus próprios olhos o milagre do modelo de vida dos americanos e a qualidade de suas instituições” (TOTA, 2014, p. 120). Anísio Teixeira, Érico Verissimo, Monteiro Lobato e outros figuram na lista dos que foram conhecer objetivamente o estilo de vida que os livros anunciavam. Essa fase intensa de intercâmbio cultural e científico fundamenta a base de acordos bilaterais posteriores e é um dos instrumentos principais de disseminação do "poder suave" dos Estados Unidos. Reforça essa ideia a quantidade de estadunidenses que, no dizer de Moura (1984) e Tota (2014), 'invadiu' o Brasil, penetrando em universidades, fundações culturais, Forças Armadas, instituições políticas, com o propósito de participar de intercâmbios culturais, científicos ou econômicos no Brasil.

A penetração ideológica também se deu por meio do ensino aprendizagem da língua inglesa, por meio de uma série de ações desenvolvidas pelo governo dos Estados Unidos destinadas à difusão deste idioma. À época, como informa Moura (1984, p. 48),

[...] se ampliou a atuação dos institutos culturais americanos em território brasileiro. Embora tivesse aparecido pouco antes da guerra, o IBEU (Instituto Brasil-Estados Unidos) ganharia um formidável impulso nesse momento, constituindo não apenas um centro difusor da língua inglesa, mas também um centro de atividades culturais variadas (palestras, concertos etc.) de importância crescente. 
A circulação e veiculação do inglês por meio de escolas bilíngues e o lugar de poder que essa LE passou a ocupar na sociedade brasileira resultam na tendência de escolarização internacionalizada prontamente recebida pela sua elite. Ao ser interpelada pela ideologia do empoderamento social que falar inglês lhe facultaria, a elite aderiu de pronto ao modelo educacional americano. Isso, talvez, justifique a ampliação daquelas escolas para suprir a demanda crescente de matrículas (MOURA, 1984). Segundo Moura, começa aí o declínio do francês como a língua da elite cultural e a ascensão do inglês. Ao destronar a popularidade do francês — que de chique passou a ser considerado démodé —, o inglês desponta como símbolo de modernização, o que contribui sobremaneira para colocar na moda tudo que viesse dos Estados Unidos. Não por acaso, isso se repetiu no plano dos intercâmbios educacionais.

Esse momento da história registra a aproximação entre Estados Unidos e Brasil, que foi continuada pelo governo militar (1964-85), pelo governo da chamada Nova República e pelas ações desenvolvidas pela comissão Fulbright. Criada em 1957, esta comissão promove o intercâmbio entre os dois países, em especial através da oferta de bolsas de estudo.

Um desses programas, o PDPI, será discutido neste estudo à luz da narrativa de professores que foram selecionados para estudar inglês em Nova York, na edição winter (inverno) 2013.

\section{DELINEANDO A PESQUISA}

Esta investigação é um recorte da minha tese de doutoramento intitulada "Yes! Temos Professores com Formação nos Estados Unidos" - narrativas de professores de inglês intercambistas do programa Fulbright (CRUZ, 2017). Naquele estudo a formação do professor de língua estrangeira foi discutida à luz da narrativa dos docentes entrevistados sobre a experiência de estudar fora do Brasil.

O corpus deste estudo é formado pela narrativa oral de cinco professores de inglês, atuantes nos ensinos fundamental e médio de escolas públicas. Estes docentes participaram do Programa de Desenvolvimento Profissional para Professores de Inglês (PDPI), organizado pela CAPES juntamente com o Programa Fulbright, o qual envia docentes de várias disciplinas para fazer curso no exterior em sua área de conhecimento.

Norteada pela História Oral e a Análise do Discurso pêuchetiana, reconstruí os relatos memoriais dos docentes, por meio dos quais empreendi uma análise interpretativa da narrativa dos entrevistados. Cumpre informar que, para resguardar os 
docentes antes de proceder às entrevistas, detalhei a cada participante os procedimentos da pesquisa. Orientada pelo que sugere Celani (2005, p. 110), nenhuma entrevista foi iniciada "[...] sem o consentimento informado, esclarecido ${ }^{3}$, na forma do diálogo contínuo e reafirmação de consentimento ao longo da pesquisa”. Esse diálogo inicial foi essencial para que eu pudesse me inteirar do nível de compreensão dos docentes acerca dos propósitos da pesquisa, ao mesmo tempo em que lhes assegurou o direito de desistir de participar do estudo a qualquer momento.

Prestados estes esclarecimentos nas sessões seguintes (re) conto o que ouvi dos docentes entrevistados. É essa história narrada pelos docentes tecida por fios de uma memória discursiva sobre a excelência da educação dos Estados Unidos e sobre o poder e domínio que os países de "primeiro mundo" exercem sobre os países "periféricos" que busco reconstruir neste estudo.

\section{SOBRE O PROGRAMA DE DESENVOLVIMENTO PARA PROFESSORES DE INGLÊS - PDPI}

O PDPI integra o Programa de Desenvolvimento Profissional para Professores (PDPP) que tem como característica principal promover ações em prol da mobilidade nacional e internacional dos docentes atuantes nos níveis fundamental e médio e em exercício efetivo na rede pública. Os cursos de imersão no exterior contemplam professores das ciências exatas e os de ciências humanas.

A execução do projeto conta com a ação conjunta de várias instituições. Cada uma delas tem uma atribuição específica: a CAPES banca os custos no Brasil e exterior; a comissão Fulbright gerencia o processo de seleção dos docentes e seu encaminhamento para a universidade estrangeira; o International Institute of Education ${ }^{4}$ seleciona, nos Estados Unidos, as universidades anfitriãs; e a embaixada americana no Brasil concede visto sem ônus para os professores selecionados, o que facilita a entrada deles no país.

\footnotetext{
${ }^{3}$ Acerca da identificação dos participantes, cabe ressaltar que todos concordaram com a menção de seus prenomes, aceitação formalizada mediante assinatura do Termo de Consentimento Livre e EsclarecidoTCLE.

${ }^{4}$ Fundado em 1919, o Institute of International Education é uma organização dos Estados Unidos sem fins lucrativos que busca promover o intercâmbio internacional de pessoas. Em colaboração com governos, fundações e outros patrocinadores, cria programas de estudo e formação para alunos, educadores e profissionais de todos os setores, incluindo o programa Fulbright.
} 
Como informa o relatório da diretoria de formação de professores da educação básica (doravante DEB) (2014, p. 201), os programas oferecidos pelo PDPP representam a resposta da diretoria “[...] às determinações legais de induzir e fomentar ações de educação continuada de alto nível para o crescimento profissional dos professores da educação básica". Ainda de acordo com o relatório, essa formação se efetiva com o intuito de ofertar programas que oportunizem vivências educacionais inovadoras e de padrão elevado de qualidade. $\mathrm{Na}$ vertente de cooperação internacional, tais ações se materializam mediante a imersão do docente no estudo da disciplina que leciona em uma universidade no exterior.

Dentre os intercâmbios oferecidos pelo PDPP, o de língua inglesa (PDPI) é o que mais envia professores para fazer curso no exterior se comparado com os demais. Ao longo das cinco edições de cursos de inglês no exterior para professores que lecionam esse idioma, 1.675 deles já participaram do PDPI. As bolsas foram distribuídas por região: Norte, 145; Nordeste, 546; Centro-Oeste, 222, Sudeste, 490; e Sul, 254.

\section{NOS ESTADOS UNIDOS, "VENDO COMO TUDO FUNCIONA": MALHAS DO IMPERIALISMO SEDUTOR}

O envio de estudantes e pesquisadores brasileiros aos Estados Unidos continua a evidenciar o empenho desse país em propagar seus valores e suas instituições através daqueles a quem foram concedidas oportunidades de conhecê-lo. Isso demonstra que os esforços para "americanizar" o Brasil teriam sido bem-sucedidos. Uma resposta ao sucesso dessa operação poderia ser exemplificada pelo elevado número de alunos e pesquisadores enviados para estudar em instituições daquele país. ${ }^{5}$ Se antes a iniciativa de enviar brasileiros para estudar e/ou conhecer a "América" partia do governo estadunidense, agora parte do Brasil. O volume de pessoas que escolhe os Estados Unidos como destino de intercâmbio ressoa a aceitação da ideia de ser a sua sociedade referência cultural e científica.

Ao discorrerem sobre suas percepções acerca dos Estados Unidos e de seu povo, dois professores entrevistados assim se posicionaram:

\footnotetext{
${ }^{5}$ No ranking dos 25 países que mais enviam estudantes para os Estados Unidos, o Brasil ocupa a décima posição. Esse dado vem do relatório Open Doors, sobre mobilidade acadêmica internacional no biênio 2013-4. Esse documento é publicado pelo Instituto de Educação Internacional.
} 
Essa questão do domínio americano sobre todas as coisas, inclusive muito bem passado nos filmes e músicas, a influência imensa que os Estados Unidos têm sobre os outros países, foi bem forte. A gente pode conhecer que a origem disso tudo tem a ver com aquelas histórias bem anteriores de cowboy e outras coisas. Eles têm bastante orgulho de si mesmo, eles se acham AS pessoas MAIS LEGAIS ${ }^{6}$ do mundo (LUIZA, 2014, entrevista).

Olha eu posso chocar com o que eu vou falar, mas lá eu me dei conta de quão... Acho que não é a palavra certa, quão medíocre nosso país é. A questão de estrutura para o povo lá, não é? Estar lá, vendo como tudo funciona, não é? Políticas públicas no sentido de transporte, educação, segurança. A gente podia andar a hora que fosse. Claro que tem assaltos, tem seus problemas como qualquer grande cidade, mas é diferente da gente aqui. [...] O que eu mais fiquei impressionado mesmo foi com a estrutura. A diferença de estrutura, nunca tinha viajado, foi a primeira vez. Então a gente tem... Ah! É como se fosse aqui, mas é melhor? NÃO! É TOTALMENTE DIFERENTE! Como se estivesse em outro mundo. É totalmente cem por cento diferente (KELSON, 2014, entrevista).

Ecoa nas narrativas acima, a imagem que os Estados Unidos tentaram, com resultados diferentes em cada lugar, consolidar na América Latina desde a década de 1940: a imagem de sociedade bem-sucedida, sem conflitos sociais; lugar de políticas públicas eficientes, onde tudo funciona; modelo que deveria orientar países latino-americanos em suas tentativas de modernização. Nessas passagens de relatos, o pré-constituído sinaliza a fronteira entre o discurso que veio de outro lugar e aquele reproduzido pelo sujeito; por meio deles, sentido e sujeito se colocam em movimento através do esquecimento. Da ordem do inconsciente, tal esquecimento como postula Orlandi $(2005$, p. 34) — “[...] resulta do modo pelo qual somos afetados pela ideologia. Por esse esquecimento temos a ilusão de ser a origem do que dizemos quando, na realidade, retomamos sentidos preexistentes".

Com efeito, enunciados como "domínio americano sobre todas as coisas" e "influência imensa que os Estados Unidos têm sobre os outros países" são exemplos de esquecimentos ideológicos; ressoam discursos já em circulação acerca de sentidos cristalizados sobre o "americanismo" e os Estados Unidos como "superpotência" econômica, política e educacional. A construção da representação desse país nos excertos ocorre na comparação em que o Brasil figura como "gigante atrasado e pobre" (TOTA, 2014, p. 104), materializado na representação do Brasil como país medíocre. A imagem dos Estados Unidos como país paradigmático (TOTA, 2014), modelo de sociedade a se espelhar que atravessa a fala dos docentes

\footnotetext{
${ }^{6}$ Palavras grafadas com todas as letras em maiúsculas indicam ênfase do entrevistado com mudança de tom de voz.
} 
é sintetizada no enunciado “[os Estados Unidos] É TOTALMENTE DIFERENTE! Como se estivesse em outro mundo".

Os dizeres dos docentes sobre o "domínio americano sobre todas as coisas" se sustentam em discursos atravessados por outros discursos; ou seja, as palavras verbalizadas se apresentam já sendo habitadas por outras ressonâncias (TEIXEIRA, 2005); são palavras tecidas no esquecimento e na retomada em dizeres preexistentes (ORLANDI, 2005) sobre a "hegemonia" dos Estados Unidos e a promoção de seu "poder suave" (NYE, 2002) por via de seus programas de intercâmbio educacional.

Cunhado pelo cientista político Joseph Nye (2002), o termo soft power (poder suave, força suave) foi elaborado para discutir como uma nação, um grupo político ou uma instituição consegue influenciar comportamentos e tendências mediante interpelações ideológicas, valores culturais com práticas tão sutis a ponto de, por vezes, passar quase despercebidas. Central na atual teoria das relações internacionais, esse conceito ajuda a compreender o modo como, nas relações internacionais, uma nação exerce seu poder sobre outra/as. Na narrativa dos docentes enunciados como "lá eu me dei conta [...] de quão medíocre nosso país é" e "estar ali, vendo como tudo funciona" evidenciam como o "poder suave" age sobre o sujeito: o intercâmbio lhe dá oportunidade de "constatar" a "diferença de estrutura" entre Brasil e Estados Unidos. A grandiosidade impressiona o sujeito, a ponto de voltar "maravilhado com a América" (TOTA, 2014, p. 124) e compartilhar uma visão da “[...] América como sendo um lugar quase mágico onde tudo é possível” (HESTERGAARD, 2003, p. 156).

Esse "poder suave", que se enquadra no que Tota (2014) chama de “americanismo sedutor", é uma força que age para atrair o indivíduo ao consumo de produtos culturais e à ideologia de prosperidade e progresso. A atração ocorre mediante uma ideologia programática cuidadosamente engendrada por investimentos em áreas como cultura e educação. Estes são canais de que comumente os Estados Unidos se valem para exercer seu "poder suave", ampliar sua influência internacional e obter os resultados almejados no curto prazo e no longo prazo, no processo de dominação ideológica, política e econômica.

\section{“QUANDO A FULBRIGHT CHEGOU NA MINHA VIDA. QUE BÊNÇÃO!": O SOFT POWER DO INTERCÂMBIO EDUCACIONAL}

O programa Fulbright começou a ser desenhado em 1945 por meio de um projeto de lei de autoria do senador J. William Fulbright. O projeto de lei preconizava a 
utilização de receitas dos estoques excedentes de guerra para apoiar financeiramente a difusão da boa vontade dos Estados Unidos em âmbito internacional através do intercâmbio de estudantes nas áreas de educação, cultura e ciência.

Com o objetivo de “[...] ampliar o entendimento entre os EUA e outros países" (FULBRIGHT, 2014), o programa Fulbright, afigura-se peça importante nas relações externas do país, desse modo, de diplomacia pública americana. Isso se dá porque os intercâmbios científicos, culturais e educacionais promovidos por ele são recursos utilizados como meio de fortalecer laços políticos entre seu governo e o de várias nações.

Na parceria de cooperação internacional entre Brasil e Estados Unidos, por exemplo, o programa tem como objetivo "promover a compreensão mútua entre o povo brasileiro e o norte-americano por meio de um maior intercâmbio de conhecimentos e de talentos profissionais, através das atividades educacionais" (BRASIL,1966, p.1). Desse modo, através de acordos bilaterais, que garantem fomentos a uma gama variada de projetos, financiamento de bolsas de estudo em áreas diversas e níveis de ensino o programa Fulbright enquanto instrumento do Governo, mobiliza valores como recurso para atrair brasileiros.

Cursos de imersão no exterior para professores da rede pública gerenciados pela Fulbright e CAPES constam na lista de ações da parceria entre Brasil e Estados. Na área de língua estrangeira, o Programa de Desenvolvimento Profissional do Professor de Inglês (PDPI) é o curso de educação continuada que oportuniza a professores de inglês estudar no exterior. Com efeito, ao falarem de sua participação no PDPI, os docentes relataram como foi o encontro com o programa Fulbright, como se lê neste excerto:

\begin{abstract}
A bolsa da Fulbright chegou exatamente quando eu já estava me questionando assim: "Meu Deus! O que eu estou fazendo de minha vida? Por que eu escolhi isso? Acho que tenho que ficar com o inglês porque gosto, mas não é aqui o meu lugar. Não está dando certo. Eu mal consigo falar inglês dentro da sala de aula". Quando a Fulbright chegou na minha vida. Que benção! Porque eu considero uma benção. Eu fico emocionado! Porque os Estados Unidos era um sonho que Deus me deu. Eu sou uma pessoa religiosa, eu penso que Deus realizou vários sonhos em um só: eu fui para os Estados Unidos, eu vi a neve e eu estudei inglês (WANDO, 2014, entrevista).
\end{abstract}

A narrativa em foco sinaliza não apenas o modo como o programa Fulbright chega à vida do indivíduo, mas também como este o recebe. Participar do programa se apresenta, para o sujeito, como intervenção divina que dá vigor e sentido novos à profissão professor. Assim, quando a Fulbright "chega" à vida do sujeito, suas 
incertezas parecem desaparecer. Essa inferência se apoia no qualificador 'benção', como solucionador de todos os conflitos profissionais do sujeito, tais quais dúvida em relação a escolha profissional, deslocamento no que se refere à identidade de professor de língua estrangeira, pelo qual perpassa sua dificuldade de proficiência na língua estrangeira que ensina.

Ainda que na dimensão macro o programa esteja relacionado com o soft power, na dimensão micro ele é recebido diversamente. O sujeito toma a participação no programa como resultante do seu esforço para ser bem-sucedido nas etapas de avaliação, mas principalmente como bênção divina materializada na realização do seu tríplice sonho: conhecer os Estados Unidos, ver a neve e ter no currículo profissional uma experiência de intercâmbio no exterior.

\section{"JÁ PENSOU ESTAR EM NOVA IORQUE?": NARRATIVAS SOBRE A CIDADE-DESTINO}

A cidade é um espaço urbano para o qual as definições e o modo de olhá-la não se esgotam. Como leciona Orlandi (2004), a cidade tem seu corpo significativo e nele tem suas formas. É um espaço que, por se caracterizar como fenômeno cultural, objeto de produção de discursos e imagens, produz sentido (ORLANDI, 2004). Para Canclini (2008), a cidade é o espaço onde atuamos de vários modos, guiados por nossos mapas mentais e emocionais que variam segundo os modos particulares de cada pessoa experimentar as interações sociais. Em Canclini (2008, p. 22 citando MONTERO, 1972) se lê que "[...] cada pessoa tem uma cidade que é uma paisagem urbanizada de seus sentimentos". A cidade pode ser sonhada, desejada. Pode seduzir. Pode encantar com seus atrativos. Pode despertar emoções improváveis.

Não por acaso utilizei essas atribuições adjetivas para a cidade: por elas passa o modo como os intercambistas construíram suas relações com Nova Iorque, a cidade destino do intercâmbio. Tal qual Berlim e Barcelona, dentre outras metrópoles europeias, o poder de sedução e a imagem cosmopolita de Nova Iorque se tornaram, nos últimos anos, emblema da globalização. Daí que se enquadra na configuração descrita por Canclini (2008) de cidade espetáculo. Para o autor as cidades espetáculos

São visitadas e adoradas como cidades globais, espaços demarcados onde o mundo se põe em cena por quatro razões: o intenso papel das empresas transnacionais, a mescla de culturas, a concentração de elite da arte e ciência, e o elevado número de turistas (CANCLINI, 2008, p.22). 
Os motivos elencados por Canclini (2008) encontram na cultura sua base de sustentação. Na conjuntura citada acima, a cultura atua como imã para as empresas transnacionais quando aliam facilidades econômicas de produção a ambientes estimulantes para comercializar seus produtos; o que, em geral, projeta a imagem delas no cenário mundial (COELHO, 2008).

A seu turno, o multiculturalismo evoca a imagem de cidade atenta aos valores sociais vigentes, como a diversidade cultural e étnica. Porém, ainda que a multiculturalidade faça “[...] coexistir etnias, línguas e modos de conhecer e imaginar numa mesma cidade, cristãos, islâmicos e agnósticos" (CANCLINI, 2008, p. 25), essa diversidade cultural adquire valor de agregação, de tal modo que configura mais um recurso mercadológico. Contribui para tornar a paisagem (APPADURAI, 2004) de Nova Iorque encantadora ao propagar a ideia de ser esta uma cidade onde as diferenças — os tons de pele, por exemplo — convivem em harmonia, num mosaico composto de culturas numerosas.

Tida com uma das maiores cidades e o maior centro financeiro e comercial do mundo, Nova Iorque possui o maior sistema de educação pública e privada dos Estados Unidos, universidades de renome internacional, dinamismo cultural e atrações turísticas para todos os gostos e bolsos. Com essas credenciais, não são incomuns as descrições com atributos de superlativização, como que a marcar sua imponência e o fascínio que evoca - e que é alimentado, em grande parte, pela indústria cultural. Também a indústria de turismo contribui para manter esse fascínio vivo ao divulgar a vasta oferta cultural de museus, galerias de arte, teatros e espaços de entretenimentos. Esses artifícios induzem o visitante a acreditar que tudo que acontece em Nova Iorque soa mágico.

A arte promove a cidade que promove a arte. Para alimentar esse círculo, Nova Iorque mantém a cultura e as artes como setor produtivo. Sua vida cultural é gerada, como informa Coelho (2008), pelo porcentual de $8 \%$ de mão de obra que trabalha com o que se pode chamar de cultura: arte, música, dança, produção de cinema, moda etc.

São esses $8 \%$ os responsáveis pela imagem mundial da cidade, tanto ou mais do que a imagem gerada pelos $20 \%$ que se ocupam com a economia. E a imagem de Nova Iorque é a de ser a capital da cultura. Isso atrai recursos e pessoas para a cidade e recursos que por sua vez aumentarão o capital cultural da cidade, num círculo vicioso que tem tudo para continuar crescendo por um tempo mesmo quando e depois que uma eventual crise econômica se abata sobre a cidade (COELHO, 2008, p. 65). 
No encontro da economia com a cultura, esta funciona como combustível que alimenta aquela. Não por acaso, um considerável número de pessoas escolhe Nova Iorque para morar, trabalhar, fazer turismo ou estudar. Essa preferência, talvez, torne compreensíveis as reações de grande parte dos docentes quando notificados de que Nova Iorque seria a cidade destino do intercâmbio. Eis o que os docentes disseram sobre a notificação do itinerário de intercâmbio:

Todo mundo queria ir para Nova Iorque. Eu dizia: "Eu vou para qualquer lugar. Até para a prisão de Guantánamo se me mandarem eu vou" [risos]. Quando saiu o resultado final: "Nicodemos Nova Iorque", eu quase morro, não é? Foi assim uma coisa de Deus, porque no fundo, no fundo eu também queria ir para Nova Iorque, porque Nova Iorque é Nova Iorque. Isso no nosso mundo ocidental. Nova Iorque para gente é o centro do centro do universo. De acordo com o que a gente convive com esse mundo imperialista dos Estados Unidos sobre o Brasil, a gente sabe que Nova Iorque é tudo de bom, pelo menos a gente tem essa noção. Além do glamour que pode envolver isso aí (NICODEMOS, 2015, entrevista).

Já pensou estar em Nova Iorque? Quando eu falei que ia para Nova Iorque, o pessoal aqui falou: "Égua! Tu tá brincando!?". Outros falavam: "Poxa! Verdade? Nova Iorque, que é um dos locais mais espetaculares do mundo! Nova Iorque, Deus me livre!". Loucura, não é? Fiquei muito feliz, muito feliz (VERMAR, 2015, entrevista).

Não tinha um lugar que eu desejasse ir. O que viesse estaria ótimo para mim. Para falar verdade, tinha um lugar que eu queria ir, era a Califórnia. Eu acho que eu ia gostar de conhecer a Califórnia, pelas academias de MMA [artes marciais mistas] que tem lá. Os campeões de UFC [campeonato de luta] são todos de lá, em Nova Iorque, o MMA é proibido. Para falar verdade o único lugar que eu não queria ir era Nova Iorque. Acredita? Só por conta disso: "Poxa! Eu vou para um lugar onde o MMA é proibido?". Mas tudo bem, vou para lá. Língua, não é? Valeu muito a pena. Fui para um dos melhores lugares dos Estados Unidos (KELSON, 2015, entrevista).

Situada na província de Guantánamo, a base naval dos Estados Unidos presente na ilha de Cuba desde 1903 abriga área de detenção: a prisão militar de Guantánamo, não por acaso palco de polêmicas e alvo de críticas severas de organizações ligadas aos direitos humanos. Seu histórico de abuso de força inclui tratamento desumano a prisioneiros que se traduz em práticas de tortura psicológica e física que ferem a dignidade. Vista como "mancha na história americana", a prisão compromete a imagem dos Estados Unidos no cenário internacional. Para lá são enviados prisioneiros de guerra de conflitos militares diversos, supostos terroristas e imigrantes ilegais à espera de deportação. Aprisionados há 
anos, muitos não foram julgados legalmente nem tiveram explicações sobre as acusações. Ainda assim, nutrem a esperança de conseguir liberdade. Por isso, em que pese a intenção jocosa da fala do entrevistado, é curioso que alguém diga estar disposto a ficar num lugar de degradação - onde atrocidades que anulam direitos humanos são cometidas — apenas para, supostamente, estar no lugar idealizado: os Estados Unidos da América.

Do fascínio acrítico pelo estrangeiro resultaria a atitude de subserviência. No interdiscurso, a condição de subalternidade do Brasil à hegemonia dos Estados Unidos se apresenta quando o sujeito diz que "a gente convive com esse mundo imperialista dos Estados Unidos sobre o Brasil". A admiração pelo outro é tão intensa que o sujeito emudece na hora de descrever a cidade-destino de seu intercâmbio. Mudez por onde circula pontos de não coincidência entre as palavras e as coisas (AUTHIERREVUZ, 1998). Ao explicar tal não coincidência, Authier-Revuz discorre sobre a relação entre real e nomeação do real via linguagem. Sua teoria é que a relação entre palavras e realidade é falha por ser o sujeito constitutivamente falho. Essa falta barra a possibilidade do sujeito de capturar o objeto pela letra.

Contudo, ainda que as palavras lhe faltem, ele tenta alcançá-las. Materialmente, os enunciados "Nova Iorque é Nova Iorque" e "Nova Iorque é tudo de bom" manifestam o esforço do sujeito para capturar o objeto pela língua: nomear a cidade - a realidade —, que fala por si só como centro do universo, lugar incomparável, no dizer do entrevistado. Não por acaso, ela aparece como cidade-destino preferida de quase todos os docentes; nos relatos, seu nome se associa com qualificadores superlativos, como "um dos locais mais espetaculares do mundo".

$\mathrm{Na}$ fala dos entrevistados, os qualificativos atribuídos ao lugar permitem supor que, para alguns, tão irreal quanto a cidade seria a possibilidade de conhecê-la. No relato de Vermar, esse improvável se faz perceber no uso do advérbio “já", alusivo à ideia de realização nunca antes imaginada. Essa inferência se apoia em expressões como “Égua! Tu tá brincando!” e "Poxa! Verdade?”, indicativas de certa incredulidade, isto é, de certas formações imaginárias sobre Nova Iorque como lugar muito aquém das condições materiais de um professor de escola pública.

Todavia, a fala de Kelson oferece contraponto à narrativa do fascínio por Nova Iorque. De início, ele se filia ao discurso do conformismo: "O que viesse estaria ótimo para mim”. Esse tom se dissipa quando ele pondera a possibilidade de aliar a experiência do intercâmbio a interesses particulares — "conhecer a Califórnia, pelas academias de MMA que tem lá”. Daí que “o único lugar que eu não queria ir era Nova 
Iorque", justamente onde o "MMA é proibido". A falta faria dessa cidade um lugar indesejado, de pouco interesse. No decorrer da narrativa, ele revê essa ideia da incompletude. Quando retoma o objetivo do intercâmbio - "Mas tudo bem, vou para lá. Língua, né?" —, filia-se ao discurso do deslumbramento: "Fui para um dos melhores lugares dos Estados Unidos".

A mobilidade estudantil de acordo com Murphy-Lejeunem (2002) é considerada um caso particular de imigração. Sob esta perspectiva, o participante de programas de intercâmbio, por transitar entre espaços e tempos de durações variáveis, afirma a autora, se posta entre o turista de passagem e o imigrante.

Essas duas dimensões de estudante intercambista aparecem de formas nítidas na narrativa dos docentes. Como turistas, salvo poucas sentem-se privilegiados a ponto de expressarem um entusiasmo colonizado por estar em Nova Iorque. Como imigrantes, eles se estabelecem em Nova Iorque por seis semanas, onde vivenciam uma cultura em trânsito (MURPHY-LEJEUNEM, 2002) e constroem seu repertório de experiências formadoras (JOSSO, 2004) nas situações impactantes no contato com a língua e a cultura que ela veicula.

\section{CONSIDERAÇÕES FINAIS}

Nos acordos educacionais selados entre os governos brasileiro e americano, no qual se inclui o PDPI, o intercâmbio desempenha papel estratégico no "plano de assistência" material e técnica (MOURA, 1984) dos Estados Unidos. A política da boa vizinhança" da década de 1940 continua a ser disseminada, desta feita tendo como alvo não apenas o ensino superior, mas também o ensino básico. $\mathrm{O}$ envio de professores brasileiros que atuam nos níveis fundamental e médio aos Estados Unidos continua a evidenciar o empenho desse país em propagar seus valores e suas instituições através daqueles a quem foram concedidas bolsas de estudo.

O Programa de Desenvolvimento para Professores de Inglês - PDPI por fomentar a internacionalização da educação básica, apresenta-se como estratégia do governo brasileiro para competir em uma economia política global cada vez mais multipolar (SPEARS, 2014). Ao mesmo tempo, a mobilidade geográfica relatada na narrativa dos docentes como competência desejada representa triunfo individual em uma conjuntura em que o cosmopolitismo impera como necessidade cultural, em contraposição a imobilidade e o confinamento. 
A articulação em níveis geopolíticos do programa de intercâmbio em pauta sinaliza que os projetos globais de soft power americano são aceitos de pronto pelo professor. Esta "força suave" produz subjetividades que se traduzem na realização do sonho de conhecer e estudar nos Estados Unidos.

Dado esse espaço que a educação parece ocupar, a exemplo da atenção dispensada pela OCIAA, ela se alinha nesta rubrica: “[...] atividades que podem influenciar de modo imediato no aumento de simpatia da América Latina para com os Estados Unidos" (MOURA, 1984, p. 47). Nos acordos educacionais selados, o papel estratégico que o intercâmbio desempenha nos interesses de cada país leva ao "plano de assistência" material e técnica (MOURA, 1984), empreendido pela "política da boa vizinhança" da década de 1940.

\section{REFERÊNCIAS}

APPADURAI, Arjun. Dimensões culturais da globalização: a modernidade sem peias. Lisboa: Teorema, 2004.

AUTHIER-REVUZ, Jacqueline. Palavras incertas - as não-coincidências do dizer. Campinas: ed. UNICAMP, 1998.

BRASIL. Diretoria de Formação de Professores de Divisão Básica/DEB. Relatório. 2013.

CANCLINI, Néstor Garcia. Imaginários culturais da cidade: conhecimento/espetáculo/desconhecimento. In: COELHO, T. (Org.). A cultura pela cidade. São Paulo: Iluminuras: Itaú Cultural, 2008, p. 15-31.

CELANI, Maria Antonieta Alba. Questões de ética na pesquisa em linguística aplicada. Linguagem \& Ensino, v. 8, n. 1, p.101-22, 2005.

COELHO, Teixeira. A cidade e os avatares da cultura. In: pela cidade. São Paulo: Iluminuras: Itaú Cultural, 2008, p. 63-8.

(Org.). A cultura

FULBRIGHT BRASIL. A Fulbright nos EUA, no Brasil e no mundo. Disponível em: $<$ http://fulbright.org.br/comissao/>. Acesso em: 14 jan. 2016.

HERTSGAARD, Mark. A sombra da águia. Rio do Janeiro: Record, 2003.

MOURA, Gerson. Tio Sam chega ao Brasil: a penetração cultural americana. São Paulo: Editora Brasiliense, 1984.

NYE, Joseph. Soft power: the means to success in world politics. New York: Public Affairs, 2004.

ORLANDI, Eni Puccinelli. Cidade dos sentidos. Campinas: Pontes, 2004. 
Análise do discurso: princípios e procedimentos. 6. ed. Campinas:

Pontes, 2005.

TEIXEIRA, Marlene. Análise do discurso e psicanálise: elementos para uma abordagem do sentido no discurso. 2. ed. Porto Alegre: ed. PUCRS, 2005.

TOTA, Antonio Pedro. O Amigo americano: Nelson Rockfeller e o Brasil. São Paulo: Companhia das Letras, 2014.

\section{- Fonte orais}

KELSON. Belém, PA, 23 de junho de 2014. Arquivo de mp3 (1 hora e 20 minutos). Entrevista concedida a mim.

LUIZA. São Luís, PA, 9 de julho de 2014. Arquivo de mp3 (1 hora e 10 minutos). Entrevista concedida a mim.

NICODEMOS. Miranda, MA, 10 de janeiro de 2015. Arquivo de mp3 (3 horas e 10 minutos). Entrevista concedida a mim em Miranda.

RITA. São Luís, MA, 8 de julho de 2014. Arquivo de mp3 (1 hora e 15 minutos). Entrevista concedida a mim.

VERMAR. Concórdia, PA, 25 de junho de 2014. Arquivo de mp3 (1 hora e 30 minutos). Entrevista concedida a mim.

WANDO. Bragança, 24 de junho 2014. Arquivo de mp3 (3 horas e 15 minutos). Entrevista concedida a mim. 